\title{
Scope of attention, control of attention, and intelligence in children and adults
}

\author{
NELSON COWAN and NATHANAEL M. FRISTOE \\ University of Missouri, Columbia, Missouri \\ EMILY M. ELLIOTT \\ Louisiana State University, Baton Rouge, Louisiana \\ RYAN P. BRUNNER \\ Ohio State University, Columbus, Ohio \\ and \\ J. SCOTT SAULTS \\ University of Missouri, Columbia, Missouri
}

\begin{abstract}
Recent experimentation has shown that cognitive aptitude measures are predicted by tests of the scope of an individual's attention or capacity in simple working memory tasks and also by the ability to control attention. However, these experiments do not indicate how separate or related the scope and control of attention are. An experiment with 52 children (10 to 11 years old) and 52 college students included measures of the scope and control of attention, as well as verbal and nonverbal aptitude measures. The children showed little evidence of using sophisticated attentional control, but the scope of attention predicted intelligence in that group. In adults, both the scope and control of attention varied among individuals and accounted for considerable individual variance in intelligence. About one third that variance was shared between scope and control, and the rest was unique to one or the other. Scope and control of attention appear to be related but distinct contributors to intelligence.
\end{abstract}

In the present study, we used the classic selective listening procedure of Cherry (1953) along with tests of working memory and intelligence to examine how the scope of attention (a storage function) and the control of attention (a processing function) are related during childhood development.

One of the fundamental distinctions in the field of information processing is that between storage and processing. This is certainly true in the case of working memory, which preserves a small amount of information in a readily accessible state for a limited time, allowing use of the information in an ongoing cognitive task (Baddeley \& Hitch, 1974; Miyake \& Shah, 1999). Miller's (1956) seminal study discussed limits in the number of units that can be stored at one time for immediate recall, as well as the process of forming larger units so that more information can be included in the same number of units in working memory. Subsequent work has further emphasized the importance of processes that regulate storage, such as control processes (Atkinson \& Shiffrin, 1968) and central executive processes (Baddeley, 1986; Baddeley

This work was carried out with the support of NIH Grant R01 HD21338 to N.C. Address correspondence to N. Cowan, Department of Psychological Sciences, University of Missouri, 18 McAlester Hall, Columbia, MO 65211 (e-mail: cowann@missouri.edu).
\& Logie, 1999). In the investigation of individual differences in working memory, many studies have suggested that one can capture substantial individual differences in a wide variety of intellectual aptitude measures by using tasks that combine storage with some type of processing (Case, Kurland, \& Goldberg, 1982; Conway, Cowan, Bunting, Therriault, \& Minkoff, 2002; Daneman \& Carpenter, 1980; Daneman \& Merikle, 1996; Engle, Tuholski, Laughlin, \& Conway, 1999; Turner \& Engle, 1989).

The distinction between storage and processing is important to consider within recent research on the role of attention in working memory. Emphasizing storage, Cowan (2001) reviewed a wide variety of evidence suggesting that people can retain up to about four separate chunks of information in a core faculty within working memory, with the amount increasing with age and varying among individuals. Cowan (2001) suggested that the faculty that is limited in this way is the focus or scope of attention. He proposed that the magical number 7 of Miller (1956) results from a process in which rehearsal and grouping of presented items expands the number that can be recalled so that one must limit rehearsal and grouping in order to observe the core capacity limit. Cowan, Elliott, et al. (2005) showed that the core limit in children and adults predicts performance on verbal and nonverbal intelligence subtests, picking up the same common variance as the tests that combine storage and processing. 
Lépine, Barrouillet, and Camos (2005) similarly found that a simple primary task that was paced (reading successive letters) in order to prevent rehearsal and grouping of numbers to be remembered resulted in capacity estimates that correlated well with scholastic aptitudes in a sample of sixth-grade children. These findings can be explained on the basis of a working memory capacity limit that depends on how much information can be attended at one time. The nature or difficulty of the distracting task is not critical, provided that rehearsal and grouping are blocked (see also Conlin, Gathercole, \& Adams, 2005; Cowan, Elliott, et al., 2005; Friedman \& Miyake, 2004).

There are also other, slightly different ways to conceive of the processing system that are still fundamentally compatible with the present research aim inasmuch as they allow that attention may be used for working memory storage. The working memory capacity limit may be the amount that can reside in the fringe-rather than the focus proper - of attention, as was suggested by Oberauer, 2002, or it could be only one of several independent types of attention with separate capacity limits, as was suggested by Woodman, Vogel, and Luck, 2001. It seems likely that attention would also be required for storage in the episodic buffer that was proposed by Baddeley (2000). That buffer was said to be capacity limited (Baddeley, 2001) and responsible for retaining features in working memory that are abstract rather than modality or code specific, and for retaining links between different kinds of features. In contrast, other types of storage in this model that comprise phonological and visuospatial storage are assumed not to require attention for memory maintenance (Baddeley, 1986; Baddeley \& Logie, 1999).

In the tasks used by Cowan, Elliott, et al. (2005) to measure the scope of attention, information was presented in a visual array with too much information to be rehearsed or grouped, or in an auditory sequence too rapid to be rehearsed or grouped. Therefore, when the stimulus presentation ended, participants presumably had to transfer items individually from a sensory memory (or a set of activated features in memory) into the focus of attention to be recalled or retained during a retention interval. Even though sensory memory can include a rich set of features for many items, the capacity of the focus of attention is limited, and it apparently limits short-term recall to about four items in adults in such cases - an amount that develops in childhood and differs somewhat among individuals. These measures of capacity correlated with the more typical storage-and-processing tasks and also with intellectual aptitudes, with all three constructs sharing considerable variance.

In children who are too young to rehearse or group items, even the items within a simple digit span test presumably must be retained with the use of attention to store some of the items. We suggest that for that reason even digit span had a high correlation with intellectual aptitudes for second- and fourth-grade children, though not for sixth-grade children or adults (Cowan, Elliott, et al., 2005; cf. Hutton \& Towse, 2001).
Other studies have instead emphasized that what is important in working memory-accounting for individual differences in intellectual aptitudes - is some type of processing that involves the control of attention. Studies relating working memory to attention have included findings of the inhibition of proactive interference from previous trials (Gray, Chabris, \& Braver, 2003; Lustig, May, \& Hasher, 2001) and findings that indicate attention is needed to attain a goal that is difficult in light of prepotent but incorrect responses. The latter include the goal of naming the color of ink of a word that spells out a different color (Kane \& Engle, 2003; Stroop, 1935), the goal of making eye movements away from rather than toward an object appearing on the screen, an "antisaccade" movement (Kane, Bleckley, Conway, \& Engle, 2001; Unsworth, Schrock, \& Engle, 2004), the goal of focusing attention on a ring rather than on a disc in space (Bleckley, Durso, Crutchfield, Engle, \& Khanna, 2003), and the goal of concentrating attention on a message presented to one ear so effectively that one does not even notice his or her own name in a different message presented to the other ear (Conway, Cowan, \& Bunting, 2001). In most cases, it has been the correlation between the control of attention and working memory tasks that was measured.

Despite the theoretical thrust of the controlled-attention view, there actually have been very few studies that have obtained correlations between attention-related processes and tests of intellectual aptitudes. Schweizer and Moosbrugger (2004) did so with complex attention tasks that may have had a vigilance component (i.e., sustained attention across time). They did find a relation between attention and intelligence, as well as a working memory component partly independent of the attention component. Whether the attention or the working memory component accounted for more variance in intelligence depended on which intelligence test was used. Gray et al. (2003) obtained neuroimaging data indicating that high fluid intelligence scores were related to activity in lateral prefrontal and parietal regions. The discriminating neural activity was obtained in an $n$-back task, specifically on high-interference trials in which familiar lures were presented. According to some findings, it appears that the correlation between aptitudes, working memory, and attentional control is not ubiquitous; it may include the processes of updating attention, but not the inhibition of irrelevant stimuli or shifting of attention (Friedman et al., 2006; Oberauer, Lange, \& Engle, 2004).

One novel development of the present study was to examine the relation between intelligence and attention using a measure of attention derived from a classic procedure from cognitive psychology, in particular, a version of the selective-attention procedure (Cherry, 1953; Conway et al., 2001; Moray, 1959; Wood \& Cowan, 1995). It is closely related to Conway et al.'s (2001) study, in which they observed that high-span participants were less likely to notice their names when they were presented in a spoken message to be ignored. The difficulty with that task is that it yielded only a single name-recognition trial 
per participant, after which the participant was no longer naive. In our task, participants concurrently received a spoken string of digits and a visual string of letters. In one condition, there was a task that involved monitoring the visual stream, whereas in another condition it was the acoustic stream that was to be monitored. This monitoring task was followed by a cue to recall the stream that had been monitored or the stream that had not. Even though participants were aware that either stream could be tested, the notion of this monitoring task was that efficiently carrying it out required more attention to be devoted to the monitored channel than to the other channel and presented an opportunity to encode the attended items in a way that assisted in recall. Therefore, as a measure of the control of attention, we used the benefit for recall when a channel was monitored as opposed to not monitored in the dualtask situation.

It is also unclear from past studies whether measures taken to reflect the control of attention (see, e.g., Conway et al., 2001) and those taken to reflect the scope or capacity of attention (Cowan, Elliott, et al., 2005) are related or independent. Some investigators consider storage and processing to be independent in situations in which storage apparently does not depend on attention or central executive processing (e.g., Cocchini, Logie, Sala, MacPherson, \& Baddeley, 2002; Duff \& Logie, 2001; Oberauer, Demmrich, Mayr, \& Kliegl, 2001). However, it is possible to consider something slightly different, a view in which there are storage and control aspects of attention that are themselves separate. More research is needed to clarify this issue. In many studies, it is left unspecified. For example, the updating of working memory has been found to correlate with intellectual aptitude (Friedman et al., 2006); however, updating could theoretically involve both a storage component and a processing component, and it is not clear to what extent each of these is critical for individual differences in task performance. According to the theoretical view of Cowan $(1995,1999)$, there should be some separation of attention-demanding processing and storage functions, even though they are related. The parietal areas of the brain should be more heavily implicated as important for the focus of attention or attentive storage of information, whereas the frontal areas should be more heavily implicated in the control of attention. Postle, Berger, and D'Esposito (1999) indeed found frontal regions of the brain to be more involved in the control of attention and posterior regions to be more involved in working memory storage (see also Posner \& Petersen, 1990; Postle, Druzgal, \& D'Esposito, 2003; Todd \& Marois, 2004; Vogel \& Machizawa, 2004). Nevertheless, given how heavily integrated the frontal and parietal areas are, it remains quite possible that individuals who are relatively good at processing using controlled attention could be the same individuals who are relatively good at storing information in the focus of attention.

We investigated the relation between a task taken to reflect attentional control (described above) and a task taken to reflect the capacity or scope of attention. To examine the latter, we used a measure that has been widely researched in recent literature - a two-array comparison procedure developed by Luck and Vogel (1997). For this task, on each trial an array of colored squares is presented and is followed by a second array that is identical to the first or that differs in the color of just one square. The task is to indicate whether there has been a change. Very distinctive colors are used, and there is a brief delay between arrays, thus the task is one that depends on the ability to remember the first array in order to compare it with the second array. In the version of the task that we used, a cue surrounded one square in the second array. The instructions were that if any square had changed, it would be the encircled square. That instruction limited the task to a single decision per trial. The fact that the squares were delivered in a simultaneous array that soon disappeared made it difficult to rehearse the items. This point is supported by evidence demonstrating that array comparisons are disrupted by overt response retrieval placed in the delay between the two arrays, presumably usurping attention, but that they are not greatly disrupted simply by a silent memory load or articulatory suppression between the two visual arrays (Cocchini et al., 2002; Morey \& Cowan, 2004, 2005; Stevanovski \& Jolicœur, 2003). Presumably, silent maintenance of a verbal memory load can rely on a phonological storage and rehearsal process (Baddeley, 1986; Gathercole \& Baddeley, 1989), unlike a spoken load. Further supporting an attentional account of visual array memory, visual array comparisons are most strongly interrupted on trials in which the response to the recited verbal load is incorrect. Attempts to correct the error presumably drain attention from maintenance of the visual array (Morey \& Cowan, 2004).

We examined both age group differences and individual differences within an age group in fourth-grade children and college students. Developmental study can help in understanding working memory both by supplying a wide range of variance in ability and by allowing an examination of the consequences of strategic differences between children and adults.

A comparison of children and adults possibly could allow an examination, in an amplified manner, of findings that have been observed using individual differences among adults. For example, one of the best arguments for the involvement of the control of attention in working memory is that individuals who have high working memory spans are much more affected by dividing attention during a memory task than are individuals with a low working memory span (Kane \& Engle, 2000; Rosen \& Engle, 1997). The theoretical explanation is that high-span individuals are more likely to carry out the memory task using control of attention, whereas low-span individuals tend to use only automatic processes that are not greatly interrupted by dividing attention. If that explanation is valid, the prediction is that children should be much less affected by diverting attention during a memory task than adults (for reviews indicating poorer control of attention in children than in adults, see Doyle, 1973; Gomes, Molholm, Christodoulou, Ritter, \& Cowan, 2000; Guttentag, 1997; Lane \& Pearson, 1982; Plude, Enns, \& Brodeur, 
1994). We used the youngest children who could reliably carry out the dual-task procedure in pilot work. These 10- and 11-year-olds were still young enough so that both their control of attention and their use of rehearsal strategies (see, e.g., Bjorklund \& Douglas, 1997; Ornstein \& Naus, 1978) were expected to be markedly inferior to those of adults.

There are many differences between processes in the visual and auditory modalities. There appear to be differences in the typical rate at which items can be processed and a greater facility with spatial arrays in the visual modality and temporal sequences in audition (Cowan, 1988, 1995; Penney, 1989). For this reason-as we discovered in pilot work-it is not easy to develop tasks in which the role of the distribution of attention across modalities can be examined (cf. Jolicœur, 1999; Tombu \& Jolicœur, 2003). In order to achieve effective manipulations of attention in both children and adults, it proved necessary for us to use more stringent requirements for visual attention than for auditory attention, perhaps because speech perception is a better-learned, more automatic skill than reading.

Finally, for an efficient comparison of working memory and attention tasks with intelligence, two measures of intelligence were excerpted from the fourth edition of the Stanford-Binet Intelligence Scale (Thorndike, Hagen, \& Sattler, 1986). In a pattern-analysis task, a complex angular shape was to be reconstructed by arranging blocks with simpler triangular shapes on them. In a vocabulary task, the meanings of various words were to be explained. The Stanford-Binet was the most standard test that we could use, because we were asked by the school system to avoid the Wechsler tests (which were being used as a screening device for the gifted-student program). The two subtests were chosen because of the following properties: (1) within a factor analysis across ages (Thorndike et al., 1986 , p. 54), these subtests had relatively high loadings on a $g$ factor reflecting the commonality among all subtests (vocabulary, .76; pattern analysis, .67); (2) vocabulary was a clear example of a verbal, crystallized intelligence subtest, with the highest loading of any subtest on a verbal factor (.47) and low loadings on other specific factors; and (3) conversely, pattern analysis was a clear example of a nonverbal, fluid-intelligence subtest, with the highest loading of any subtest on an abstract-visual factor (.65) and low loadings on other specific factors.

Four general predictions for this study can be articulated: (1) The most important experimental prediction of the study - extrapolating from Rosen and Engle (1997) and Kane and Engle (2000) - is that diverting attention should affect memory much more in adults than in children. (2) Additionally, the visual array task should reveal growth with age in the scope of attention as measured in the array comparison task, replicating a previous study (Cowan, Elliott, et al., 2005). (3) It is also possible to make predictions about within-age correlations between tasks. If at least part of the variance in aptitudes is shared between the attentional-control (selective attention) task and scope-of-attention (visual array) task, that will provide validity for the notion of a common attentional resource that is an important contributor to intelligence. It is of considerable interest to know whether two very different tasks that have been theoretically associated with different aspects of attention (processing vs. storage aspects) will prove to be complementary or redundant in the accounted-for variance. (4) Finally, there should be at least two age-group differences in these correlations. First, if the control of attention is more important for performance in high-span participants (see, e.g., Kane \& Engle, 2000), then individual differences in the control of attention could play a smaller role in children than in adults because children have lower spans. Second, if simple list-memory measures provide an index of the scope of attention in children too young to rehearse (Cowan, Elliott, et al., 2005), then these measures should correlate with intelligence in the children, who can be considered to be at the upper end of the nonrehearsing range (e.g., Ornstein \& Naus, 1978).

\section{METHOD}

\section{Participants}

The 104 participants included 52 children ( 25 female, 27 male) with a mean age of 10 years and 10 months ( $S D=5.18$ months) who were recruited from the Columbia, Missouri, public school district and received $\$ 20$ and a book for their participation, as well as 52 University of Missouri, Columbia, undergraduates (38 female, 14 male) with a mean age of 20 years and 6 months ( $S D=41.41$ months) who received course credit in return for their participation.

\section{Design}

Given our interest in comparisons between individuals within a group, procedures were administered in a standard order, including (1) an auditory digit span test, (2) a visual letter span test, (3) a dual task to measure capacity, in which auditory digits and visual letters were presented together, (4) a visual array task to measure capacity, (5) a vocabulary test, and (6) a pattern-analysis test. Procedures 1 and 2 were used to adjust the difficulty levels for Procedure 3 on an individual basis. Procedures 3 and 4 provided measures of working memory capacity, whereas Procedures 5 and 6 provided evidence on intellectual abilities.

\section{Apparatus, Stimuli, and Procedure}

The study took about $1.5 \mathrm{~h}$ per participant. The first four tasks were computer administered and the final two tasks were administered according to the instructions for the Stanford-Binet test (Thorndike et al., 1986).

Auditory digit span task. Every participant received the same sequence of digit lists, beginning with six 3-digit lists and proceeding to a test that included three lists per length, starting with 3 -digit lists and increasing by one item at a time to a maximum of 9-digit lists. However, the test ended if all three lists of a particular length were recalled incorrectly. For each list, the stimuli that made up the standard sequence had been drawn randomly — without replacement - from the set of digits 1-9.

At the beginning of each trial, a white fixation cross appeared in the center of a black screen. After $750 \mathrm{msec}$, the fixation cross disappeared and playback of the digit list began. Digitized recordings of the stimuli were presented in a male voice at a fast rate of $500 \mathrm{msec}$ per item (i.e., 2 items/sec). All digits were within a range of 65-70 dB(A) - as measured with a sound level meter and accompanying earphone coupler-and were presented through TDH-39 
audiological headphones. After each list, a series of blank line segments that were arranged in a row with one segment per list item served as a recall cue. As the participant typed the response, the recalled numbers - displayed in a 30-point font-filled in the space that had been previously occupied by the blank line segments. Participants were instructed to use the keyboard's number keypad to type the digits in the presented order. They were asked to try not to make mistakes and were given an opportunity to review and correct the answers before pressing a key to indicate that these answers were final. (Cowan, Nugent, Elliott, Ponomarev, \& Saults [1999] previously showed that the age difference in digit span within this age range is no larger when a keyboard response is used than when a spoken response is used.) A participant's digit span was taken to be equal to the length of the longest digit list successfully recalled.

Visual letter span task. The letters A, E, C, F, R, H, I, O, and L were used as stimuli. (There were the same number of choices as in the auditory case, and these letters were selected because they are easily discriminable.) The keys corresponding to these letters were marked with colorful, reflective stickers. These stimuli were presented in 30-point font (15 mm tall) at a rate of one letter per second, with each letter replacing the previous one in the center of the screen. In all other ways, the visual letter span tasks were administered and scored in the same fashion as the auditory digit span task.

The use of different materials for visual and auditory spans made it impossible to compare the modalities directly. However, comparing them was not a goal of the present study, whereas making the task instructions simple and easy to follow, segregating stimuli in the two modalities, and eliminating intragroup variations in the presentation method (to allow the most powerful examination of individual differences in ability) were the central aims.

Dual-modality memory task. This task included three different types of trial blocks that were distinguished by the stimulus arrangement and the task instructions. In the first type of trial block (auditory only), participants were to listen carefully to a digit list on each trial. Only spoken digits were presented, and they were to be recalled in order using the keypad. In the second type of trial block (attend auditory), participants were to listen carefully to the digit list on each trial and ignore a list of letters that were visually presented one at a time. Following each pair of lists, however, a cue appeared (a picture of an eye or an ear) that indicated whether the list of spoken digits or printed letters should be recalled in order using the keypad. Half of the time, the list in the to-be-ignored channel was the one to be recalled. In a third type of trial block (attend visual), the presentation was the same as in the second type, but participants were to ignore the spoken digits and detect vowels within the stream of printed letters, pressing the " 1 " key every time a vowel occurred. Following the lists (as in the second type of trial block), a cue appeared that indicated which modality should be recalled in order using the keypad.

Despite the fact that trial types were blocked by the modality to be attended during the list presentations, each trial also began with the image of an eye or an ear to remind the participant of the attentional instructions. Thus, on half the trials the eye or ear icon that was presented before the lists as an attention cue did not match the icon that was presented after the lists as a recall cue. For an example corresponding to a trial within Block Type 2 or 3 following the attention cue, see Figure 1.

When printed letters were presented (Block Types 2 and 3), they were presented with the same timing as in the visual letter span task, at a $1 \mathrm{item} / \mathrm{sec}$ rate. The auditory stimuli were presented at a faster, 2 items/sec rate, beginning halfway through the visual sequence so that both visual and auditory sequences, which always included identical numbers of stimuli, ended simultaneously. When the printed letters were omitted (Block Type 1), the spoken digits were presentedagain at a 2 items/sec rate - after the same delay as if the letters had been presented. The recall cues were $7.3 \times 11.3 \mathrm{~cm}$, monochromatic pictures of either an eye or an ear that were displayed in a white frame against a black background. These recall cues were displayed immediately after the presentation of the last digit and letter and remained on the screen until the participant pressed the space bar. For trials presenting both visual and auditory stimuli, the occurrence of either an eye or an ear recall cue was randomly determined, with the constraint that an equal number of each cue type be presented for

Trial block instructions: "Press a key for each printed vowel and ignore the spoken digits," or "Ignore the printed letters and listen to the digits."

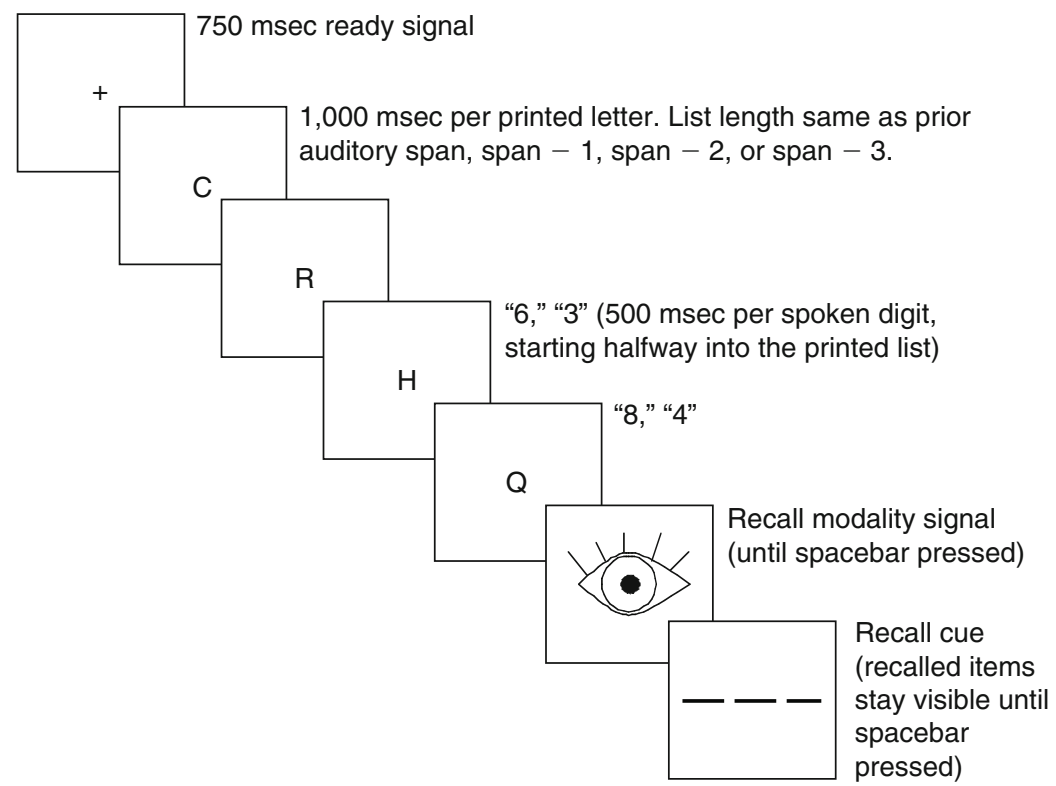

Figure 1. Illustration of a four-item trial in the dual-modality task. List lengths were adjusted in relation to the auditory span task. 
each task at each list length. After the space bar was pressed, a recall screen appeared that was identical to that used in the auditory digit and visual letter span tasks. After filling in all the blank lines, the word "CORRECT" flashed on the screen. If the participant was satisfied with his or her answer, the "Y" key was to be pressed; otherwise, the participant could press the "N" key and reenter his or her response. The space bar was to be pressed to continue.

There were three practice trials for each type of trial block, presented in the following order: Block Type 1, 2, and then 3. Blocks of 16 test trials were then run in the following order: Block Type 1, 2, 3, 3,2 , and 1 , for a total of 96 trials. In each block, list lengths were adjusted in relation to the longest auditory list length that was correctly repeated in the auditory digit span task, termed the span. Shorter lengths were defined relative to span. For example, "span - 2" refers to a list length that is two items shorter than span. The list lengths were changed within a block in the following fixed order, with a list length defined across runs of two trials: span, span -1 , span -2 , span -3 , span -3 , span -2 , span -1 , and span.

Visual array task. The visual array task was modeled after an experiment in Luck and Vogel (1997). One array of 4, 6, 8, or 10 colored squares was presented, followed by a second array that was identical or that differed from the first array, but only in the color of one square. One square in the second array had a circle around it to indicate that if any square had changed color, it had been that one. This experimental procedure was considered the most appropriate for judging storage capacity because only one decision had to be made (on the cued square), limiting interference. Trials of all array sizes (4, 6,8 , and 10 items) were randomized together in the experiment.

On each trial, which was initiated by the participant, a fixation cross was presented for $1 \mathrm{sec}$ and was followed by a presentation of the first array of squares for $250 \mathrm{msec}$. At an estimated viewing distance of $50 \mathrm{~cm}$, the array fell within a $9.8^{\circ}$ horizontal $\times 7.3^{\circ}$ vertical visual angle of view. Squares were placed randomly except that the minimum separation between squares (center to center) and between any square and the fixation point was $2.0^{\circ}$. Each square was $0.74^{\circ} \times$ $0.74^{\circ}$ in visual angle. The square colors were red, blue, violet, green, yellow, black, and white, and each square was assigned a color randomly with replacement (i.e., there was no restriction against the same color appearing more than once in an array - a method that minimizes the ability to answer correctly on the basis of guessing). There was a 1-sec blank interval with a light gray screen between the offset of the first array and the onset of the second array. The target square in the second array - the one that was to be judged - was surrounded by a black circle $1.48^{\circ}$ of visual angle in diameter. The participant answered by pressing one computer key to indicate that the color had changed between arrays (the "/" key) or another key to indicate that it had not changed (the " $z$ " key). If it had changed, any postchange color was possible, whether or not that color had already been present elsewhere in the array. The intertrial screen was light gray. There were 64 trials at each array size, or 256 trials in all.

Aptitude tests. In order to examine the participants' aptitude, two subtests of the Stanford-Binet Intelligence Scale (Thorndike et al., 1986 ) were used. In the vocabulary subtest, words were presented in written form and pronounced aloud by the experimenter. The participant's task was to explain the meaning of each word. In the pattern analysis test, designs were constructed by the experimenter from a set of black and white blocks according to test instructions, and the participant's task was to reproduce each pattern with a duplicate set of blocks before a time limit that varied, depending on the level of the task. The test began at a different point for each age group, but was designed to assess the absolute performance level in any case. Thus, the rare participant who did not perform up to the age-specific entry level of the test would then move backward to easier levels of the test rather than progress to harder levels.

\section{Calculation of Capacity Scores}

Measures were designed to express performance in terms of capacity. For list-recall tasks (attended and unattended spoken and
Table 1

Means and Standard Deviations (SDs) for All Tasks in Each Age Group

\begin{tabular}{|c|c|c|c|c|}
\hline \multirow[b]{2}{*}{ Measure } & \multicolumn{2}{|c|}{ Children } & \multicolumn{2}{|c|}{ Adults } \\
\hline & $M$ & $S D$ & $M$ & $S D$ \\
\hline \multicolumn{5}{|l|}{ Auditory Span } \\
\hline Maximum correct & 6.33 & 1.12 & 7.13 & $1.09^{*}$ \\
\hline Average number correct & 4.03 & 0.57 & 4.51 & $0.49^{*}$ \\
\hline \multicolumn{5}{|l|}{ Visual Span } \\
\hline Maximum correct & 5.10 & 0.98 & 6.31 & $0.98^{*}$ \\
\hline Average number correct & 3.22 & 0.57 & 4.07 & $0.56^{*}$ \\
\hline \multicolumn{5}{|l|}{ Dual-Modality Task } \\
\hline \multicolumn{5}{|c|}{ Mean number of items correct } \\
\hline Attended auditory & 3.59 & 0.88 & 4.26 & $0.89^{*}$ \\
\hline Attended visual & 1.68 & 0.71 & 3.00 & $1.01^{*}$ \\
\hline Ignored auditory & 3.35 & 0.88 & 3.36 & $0.66^{\dagger}$ \\
\hline Ignored visual & 1.69 & 0.65 & 2.26 & $0.67^{*}$ \\
\hline Auditory alone & 3.98 & 0.84 & 4.76 & $0.80^{*}$ \\
\hline Vowel detection $d^{\prime}$ & 1.93 & 0.90 & 2.94 & $0.94^{*}$ \\
\hline Visual Array Capacity & 2.41 & 1.30 & 3.59 & $0.97^{*}$ \\
\hline \multicolumn{5}{|c|}{ Stanford-Binet Intelligence Scale } \\
\hline \multicolumn{5}{|c|}{ Vocabulary } \\
\hline Raw & 27.02 & 3.12 & 37.44 & $3.85^{*}$ \\
\hline Age-adjusted & 53.37 & 6.03 & 53.37 & $6.70^{\dagger}$ \\
\hline \multicolumn{5}{|l|}{ Pattern analysis } \\
\hline Raw & 34.12 & 5.75 & 39.60 & $3.52^{*}$ \\
\hline Age-adjusted & 55.69 & 7.31 & 53.71 & $4.33^{\dagger}$ \\
\hline
\end{tabular}

Note-Visual Array Capacity refers to the measure of Cowan (2001). ${ }^{*}$ Age difference $t$ test $\left(p<.05\right.$, two-tailed). ${ }^{\dagger}$ n.s.

printed lists), given that a small set of items was used, the score on each trial was taken as the number of items recalled in the correct serial positions, as has been done in previous work (e.g., Cowan et al., 1999). For the visual array task, two formulae were tried out. One of these was described by Pashler (1988). His formula was based on the idea that $k$ out of $N$ items in the first array are transferred into working memory. If a changed item happens to be in working memory (with probability $k / N$ ), then the change will be noticed. If no change is noticed, the participant will guess that a change has occurred with probability $g$. Therefore, the capacity formula is $k=N *(\mathrm{H}-\mathrm{FA}) /(1-\mathrm{FA})$, where $\mathrm{H}=$ the proportion of hits (proportion of "change" responses on change trials) and FA $=$ the proportion of false alarms (proportion of "change" responses, when in fact no change occurred). The other formula was a modification of Pashler's formula that seemed more suitable to the present version of the task, in which a single item within the second array was cued. It is based on the assumption that the correct answer will be available if the cued item is in working memory, whether or not there is a change in color. This occurs on $k / N$ of the trials in which there is a change and (unlike Pashler, 1988) on $k / N$ of the trials in which there is no change. If a change is not detected, the participant will guess that a change has occurred with probability $g$. This leads to the formula $k=N *(\mathrm{H}-\mathrm{FA})$, as was shown previously (Cowan, 2001; Cowan, Elliott, et al., 2005, Appendix A). Theoretically, these measures should increase with stimulus set size up to capacity, after which they should reach an asymptotic level. It is only at this asymptotic level that the capacity is indicated by the measure. The measure that reaches a more stable asymptote thus is probably to be preferred.

\section{RESULTS}

First we report experimental effects with an emphasis on age group differences, and then we report correlation and regression analyses. 


\section{Children, Auditory Recall}

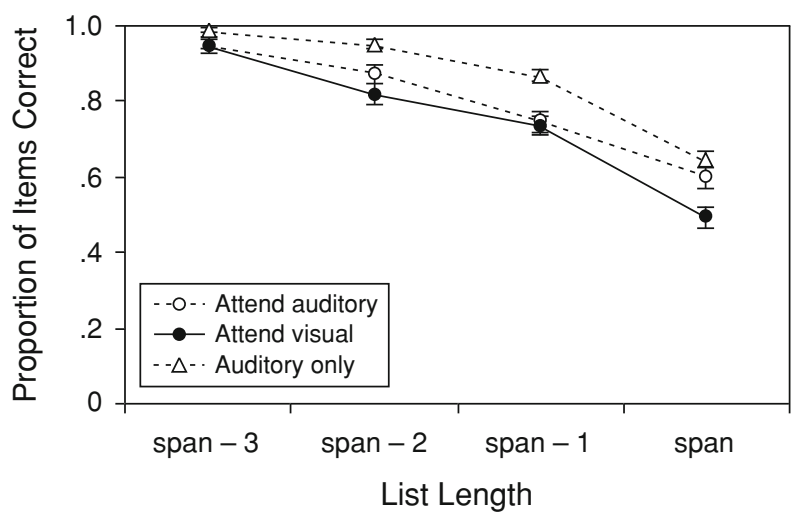

Adults, Auditory Recall

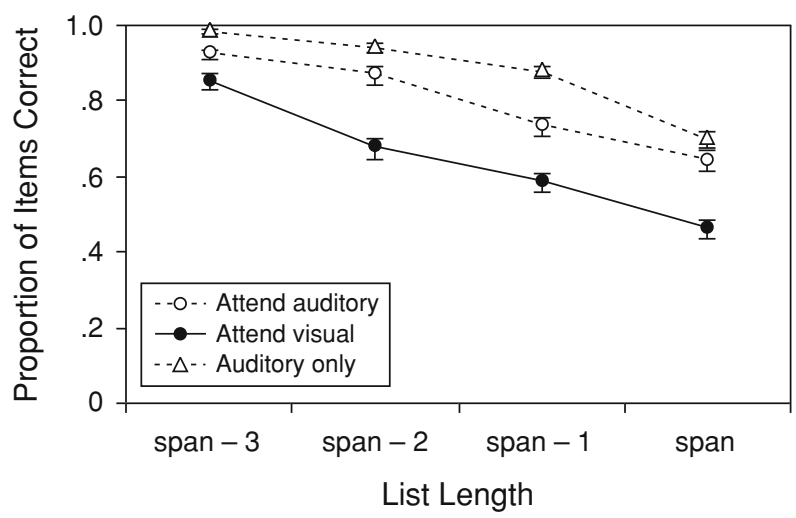

Figure 2. Mean proportion of correct items recalled per list for attended and ignored spoken digits and for an auditory-only control condition, for each relative list length $(x$-axis). Error bars are standard errors.

\section{Age Effects}

Means and standard deviations for all measures appear in Table 1. For the list-recall tasks, the number correct averaged across list lengths is reported in this table (because this measure is relatively constant across list lengths), whereas for purposes of examining the data in more detail, a proportion-correct measure will be used. Measures that produced a significant age effect in a $t$ test are marked with an asterisk to the right of the adult scores. It is clear that most measures produced significant age effects.

Auditory and visual span tasks. Two measures of spans are reported in Table 1. The first measure, maximum number of items correct, yielded the integer span that was necessary to adjust the list lengths in the list-recall tasks. However, for the sake of correlational analyses, a more sensitive measure was needed. The measure selected was the number of items correctly recalled per list, averaged across lists of all lengths. For both measures, the auditory and visual span results were both within a range that is typical for each age group, and they were significantly higher for adults.
List-recall tasks. Further analyses were undertaken to gain a better understanding of performance in the attendedand ignored-list tasks. The mean proportions of items in the list that were correctly recalled in each condition are shown in Figure 2 for auditory memory and Figure 3 for visual memory. They are shown separately for each relative list length (span -3 , span -2 , span -1 , and span) in each figure. These figures suggest that although adults recalled attended lists considerably better than they did ignored lists, this was not the case for children. The absence of an age effect for ignored auditory stimuli-unlike the other conditions (see Table 1) - can be explained on the grounds that these stimuli were truly ignored by adults but received more attention by children, who may have been unable to ignore them.

To verify this pattern of results, a $2 \times 2 \times 2 \times 4$ ANOVA was carried out on the proportion-correct scores in the bimodal trials, with age group between subjects and with three within-subjects factors: the modality cued for immediate recall (auditory or visual), its attentional status (i.e., whether the cued modality was to be attended or ignored during the list presentation), and the list length (span -3 , span -2 ,

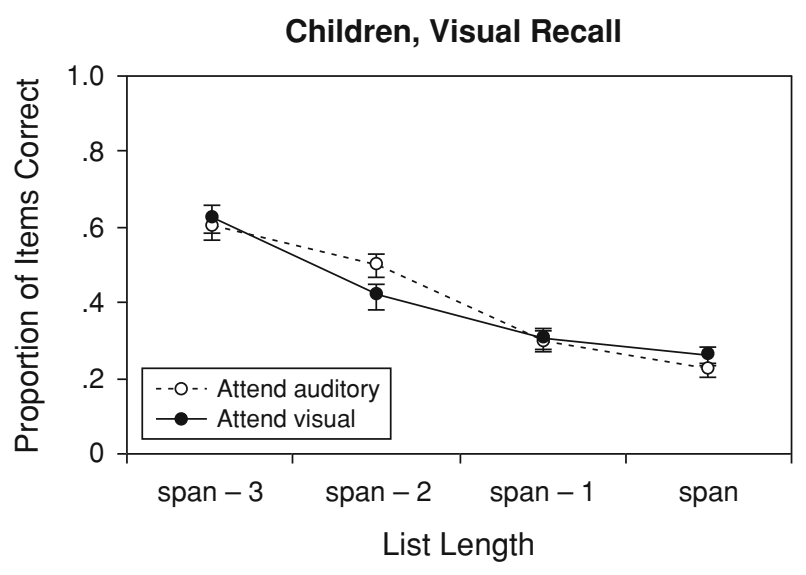

Adults, Visual Recall

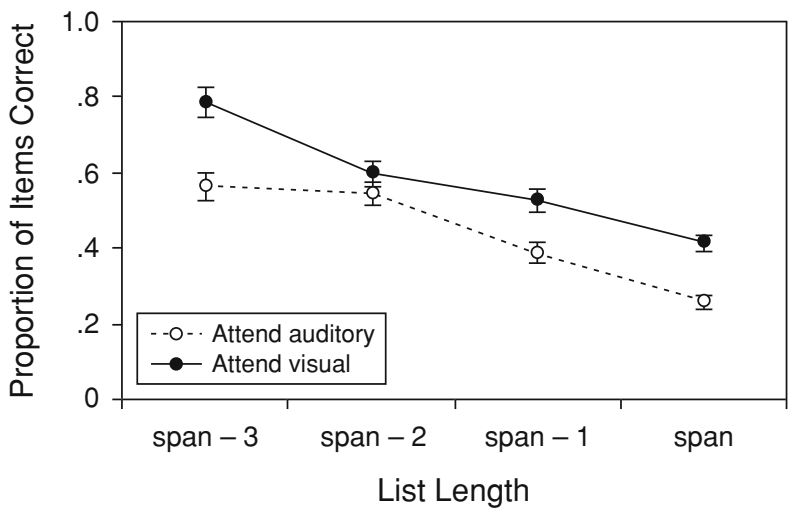

Figure 3. Mean proportion of correct items recalled per list for attended and ignored printed letters, for each relative list length $(x$-axis). Error bars are standard errors. 


\section{Subgroups Matched on Vowel Detection}

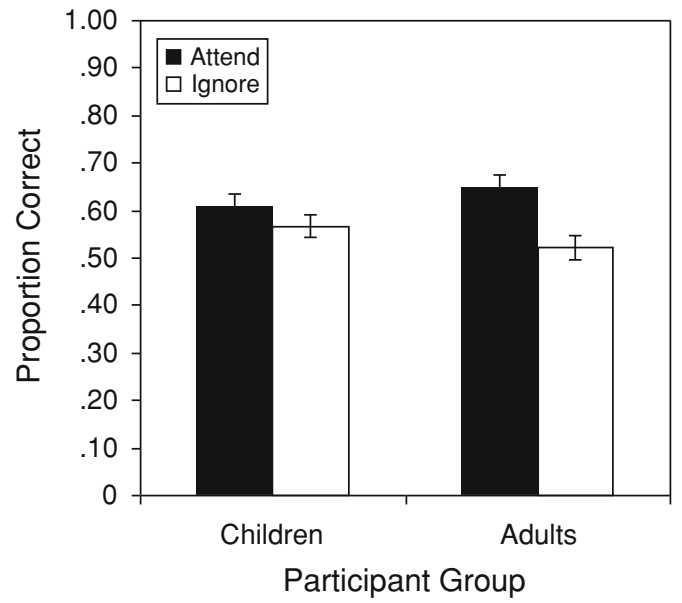

Figure 4. The interaction of age group and attention in the list recall tasks, for 30 children and $\mathbf{3 0}$ adults matched for performance $\left(d^{\prime}\right)$ on the vowel-detection task. Error bars are standard errors.

span -1 , and span length). Auditory-only trials were omitted from this analysis. For the sake of simplicity, only effects that include the age-group factor will be reported. Our measure of the proportion of variance accounted for, $\eta_{\mathrm{p}}^{2}$, is calculated as $S S_{\text {effect }} /\left(S S_{\text {effect }}+S S_{\text {error }}\right)$.

There was no main effect of age group, which was expected since list lengths were adjusted on the basis of individual spans. However, age group interacted with the modality to be recalled $[F(1,102)=34.66, p<.001$, $\left.\eta_{\mathrm{p}}^{2}=.25\right]$. Children performed much better on spoken lists $(M=.77, S E M=.02)$ than on printed lists $(M=$ $.40, S E M=.02)$, whereas in adults the difference between spoken lists $(M=.72, S E M=.02)$ and printed lists $(M=$ $.51, S E M=.02$ ) was comparatively smaller. There was a small three-way interaction of age group $\times$ modality $\times$ list length $\left[F(3,306)=4.43, p<.01, \eta_{\mathrm{p}}^{2}=.04\right]$. The age difference in proportion correct for printed lists from the shortest list length to the longest, respectively, was .06,
$.11, .16$, and .10 , favoring the adults, whereas for spoken lists - for which performance was higher overall (cf. Figures 2 and 3 ) - the differences were $-.06,-.07,-.08$, and .01 , respectively, generally favoring the children.

Most importantly, age group also interacted with attentional status $\left[F(1,102)=25.05, p<.001, \eta_{\mathrm{p}}^{2}=.20\right]$. As Figures 2 and 3 illustrate, regardless of the list length, children's memory was about the same for attended $(M=$ $.59, S E M=.02)$ and ignored $(M=.57, S E M=.02)$ lists, whereas adults' memory was much better for attended $(M=.68, S E M=.02)$ than for ignored $(M=.54$, $S E M=.02)$ lists. Newman-Keuls tests verified that the effect of attention was significant in the adults, but not in the children.

This result theoretically could have been contaminated by differences between children and adults in response strategy in a dual-task situation. Children could have chosen to attend to both modalities equally instead of allocating more attention to the modality of the primary processing task. Such a difference in strategy could explain the poorer performance in the vowel-detection task in children than in adults (Table 1). However, we checked this possibility by omitting adults with the best vowel-detection performance and children with the poorest such performance until arriving at subsamples matched in voweldetection performance $\left(d^{\prime}\right)$. Doing so resulted in $n=30$ per age group, with a vowel-detection $d^{\prime}$ of 2.47 ( $S D=$ $0.62)$ for children and $2.46(S D=0.63)$ for adults. In that subsample, there were still the same significant effects in the proportion correct, including - most importantly - an interaction of group $\times$ attentional status $[F(1,58)=6.29$, $\left.p<.02, \eta_{\mathrm{p}}^{2}=.10\right]$. This interaction is shown in Figure 4. Better memory of items in the attended modality was still a quality that applied to the adults much more strongly than it applied to the children. In fact, Newman-Keuls tests confirmed that it was significant for adults, but not for children.

Another indication that the children were not as able as the adults to modulate attention comes from a comparison of performance on ignored auditory lists compared with performance on lists that did not include visual stimuli

Table 2

Correlations Between Selected Measures

\begin{tabular}{lccccccc}
\hline \multicolumn{1}{c}{ Measure } & 1 & 2 & 3 & 4 & 5 & 6 & 7 \\
\hline 1. IQ composite & $\mathbf{. 5 5 / . 9 0}$ & .18 & .13 & $.44^{*}$ & $.45^{*}$ & $.38^{*}$ & .08 \\
2. Attention benefit (lists) & $.47^{*}$ & $\mathbf{. 7 0 / . 6 7}$ & .17 & .05 & .07 & -.22 & .01 \\
3. Vowel detection (lists) & -.08 & .02 & $\mathbf{. 8 8 / . 9 2}$ & $.39^{*}$ & -.02 & .05 & .03 \\
4. Visual arrays & $.52^{*}$ & $.34^{*}$ & .16 & $\mathbf{. 6 9 / . 7 8}$ & $.34^{*}$ & $.28^{*}$ & .25 \\
5. Visual span & .25 & $.41^{*}$ & .15 & $.38^{*}$ & $\mathbf{. 6 8 / . 7 1}$ & $.66^{*}$ & .20 \\
6. Auditory span & .23 & .18 & .16 & .23 & $.45^{*}$ & $\mathbf{. 7 4 / . 7 8}$ & -.08 \\
7. Auditory only & -.08 & .26 & .15 & .16 & -.22 & $-.29^{*}$ & $\mathbf{. 7 7 / . 6 8}$ \\
\hline
\end{tabular}

Note $-N=52$ for all correlations. The correlations below the diagonal are for adults and those above the diagonal are for children. "Attention benefit" refers to the attention-benefit ratio described in the text. The basis of the attention-benefit and auditory-only measures was the mean proportion correct for all list lengths except the shortest (span - 3). Auditory and visual spans refer to the average number correct. On the diagonal in bold: reliability statistics for adults and children. All are Cronbach's alpha measures except those for the IQ composite, which are Kuder-Richardson Formula 2 scores from the manual of Thorndike et al. (1986, p. 39) averaged across the Vocabulary and Pattern Analysis tests (vocabulary, .96/.93; pattern analysis, .94/.87). ${ }^{*} p<.05$, two-tailed. 
at all. In confirmation of what is shown in Figure 2, an analysis of proportions correct for these two types of lists in the two age groups (with list length as a second within-subjects factor) produced a condition $\times$ age group interaction $\left[F(1,102)=26.87, p<.001, \eta_{\mathrm{p}}^{2}=.21\right]$. In children, performance on ignored auditory lists $(M=.75$, $S E M=.02)$ was somewhat poorer than on auditory-only lists $(M=.86, S E M=.01)$, but in adults, performance on ignored auditory lists $(M=.64, S E M=.02)$ was much poorer than on auditory-only lists $(M=.87, S E M=.01)$. Newman-Keuls tests showed the difference to be significant at both age groups. Still, the interaction shows that the "ignore auditory" instructions were more successful in the adult group. Moreover, the same interaction was significant in the subsample matched for vowel detection performance $\left[F(1,58)=13.96, p<.001, \eta_{\mathrm{p}}^{2}=.19\right]$. (In children, $M=.73$ and .86 for ignored-auditory and auditory-only lists, respectively, $S E M=.03$ and .02 ; for adults, $M=.61$ and .86 , respectively, and $S E M=.03$ and .02.) Newman-Keuls tests again showed the condition effect to be significant at both age groups. Of course, there may have been some component of interference from visual stimuli that was not based on attention. Therefore, the comparison of attended versus ignored lists presented previously, which showed no condition difference in children and a large difference in adults, may be a purer indication of group differences in attention control.

We also compared the particular dual-modality condition in which a cue to attend the auditory channel was followed by a test of the same channel with the single-modality condition in which only an auditory channel was presented. An ANOVA of proportion correct in the two age groups (using the full sample, $N=52$ per group) with the condition (attend auditory vs. auditory only) and list length (span -4 through span) as within-subjects factors produced no main effect of age group or interaction of age group with any

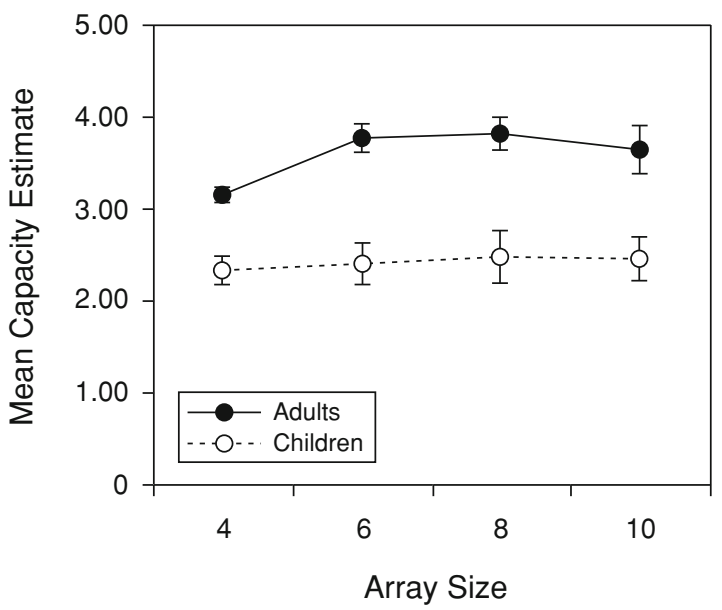

Figure 5. Estimates of adults' and children's working memory capacity for items in visual arrays of different set sizes ( $x$-axis), based on the capacity estimation formula of Cowan and colleagues (Cowan, 2001; Cowan, Elliott, et al., 2005, Appendix A). Error bars are standard errors. other factors: $F<1.05$ in each case. Across both groups, performance was better for the auditory-only condition than for the attend-to-auditory condition $[F(1,102)=69.25, p<$ $\left..001, \eta_{\mathrm{p}}^{2}=.41\right]$ (children, $M=.86$ vs. .79 ; adults, .87 vs. .79). This suggests that there may be some type of resource that is inevitably allocated to the visual stimuli that are to be ignored. For example, phonological memory for spoken items may suffer interference when people automatically and silently read the ignored letters and produce phonological representations of them. This is the converse of the cross-modal Stroop-like effect (Cowan \& Barron, 1987; Elliott, Cowan, \& Valle-Inclan, 1998) and the irrelevantspeech or irrelevant-sound effect (Colle \& Welsh, 1976; Jones, 1999; Salamé \& Baddeley, 1982), in which spoken stimuli interfere with printed words. It suggests that not only spoken stimuli but also printed verbal stimuli can have automatic access to the phonological system, as one might also conclude from the original effect of Stroop (1935).

In principle, it would be possible for a participant to close his or her eyes when the visual modality was to be ignored (counter to the task instructions). However, we found that on every visual trial in both age groups, every participant correctly recalled at least one printed letter, indicating that participants' eyes could not have been closed throughout the presentation. Moreover, as Figure 3 shows, for ignored visual lists there was a large effect of the list length with very small error bars, which could occur only if the stimuli were seen rather consistently.

Visual array task. Hits refer to detection of a change between the standard and comparison arrays, and false alarms refer to answers indicating that there was a change when in fact there was not. Collapsed across set sizes, the mean hit rate of children in the visual array task was .68 $(S D=.17)$, and the mean false alarm rate was $.30(S D=$ .18). For adults, the mean hit rate was slightly higher at .73 $(S D=.10)$, and the mean false alarm rate was considerably lower at $.17(S D=.09)$. The main analyses for this task were, however, capacity estimates as described above. An important characteristic of the estimate is that it should not change as a function of the set size above the capacity limit. Figure 5 plots one type of estimate (Cowan, 2001; Cowan, Elliott, et al., 2005, Appendix A), which was fairly constant across set sizes for the children and fairly constant for adults with set sizes above 4 . Some adults may have had a capacity higher than 4 , resulting in a ceiling effect for the estimate at that set size. Table 1 shows that this estimate increased markedly and significantly from children to adults. In contrast, the estimates using the original method of Pashler (1988) were less constant across the four set sizes: for the children, 2.75, 3.05, 3.18, and 3.35, and for the adults, 3.39, 4.36, 4.86, and 4.46.

Aptitude tests. The aptitude test scores summarized in Table 1 show that there were marked improvements from children to adults in the absolute level of performance, both on the vocabulary test and on the pattern-analysis test. Nevertheless, the age-adjusted scores were not significantly different in children versus adults. Therefore, group differences reasonably can be attributed to maturational differences rather than sample selection differences. 


\section{Correlations and Regressions}

Selected measures were used to characterize the extent to which potential indices were related to intelligence and to each other. To characterize intelligence, we used a score equal to the sum of $z$ scores for the verbal and performance measures. In order to compare the benefit of attention in the list-recall tasks with other measures, we devised a single score that would reflect that benefit. This score, termed the attention-benefit ratio, was taken as the average proportion correct on trials in which the modality to be attended was also tested, divided by the average proportion correct on trials in which the modality to be attended turned out not to be the one tested. Given that the shortest (span -3$)$ list conditions generally yielded lower standard deviations than the other three conditions, it was excluded, and this ratio was based on the averages across the three longer list conditions. This ratio for the children was 1.08 $(S D=0.29)$, and for the adults it was $1.34(S D=0.36)$. The difference was highly significant $[t(102)=3.96, p<$ $.001]$. We also included the $d^{\prime}$ measure of vowel detection for visually presented letters. This is a possible index of vigilance and the adequacy of attention to the visual modality during the bimodal presentation of lists. We included the average capacity estimate on the visual array task (the revised estimate), which presumably indicates the scope of attention (Cowan, Elliott, et al., 2005). Finally, we included the visual and auditory spans (the more sensitive, average number correct measure) and performance in the auditoryonly condition following span.

Correlations between these measures are shown separately for the adults and children in Table 2. This table shows different patterns of correlations for the two age groups, for reasons that are not difficult to understand.

Adults. In the adults (Table 2, below the diagonal), both the attention-benefit ratio and the visual array task performance showed substantial, significant correlations with intelligence. These two different attention measures also were correlated with one another. Given that the attention benefit is an attention-control measure and the visual array task is a scope-of-attention measure (Cowan, Elliott, et al., 2005), it appears that these two attention constructs have something in common.

It is useful to dissect performance into the conditions contributing to the attention-benefit ratio. In adults, the average of the ignored-modality conditions contributing to this ratio were negatively correlated with the intelligence composite $(r=-.45, p<.001)$. That is, better performance in this condition was found for individuals with lower IQ composites. However, it was not correlated with array comparisons $(r=-.17$, n.s. $)$, and the average of the attended-modality conditions was not correlated with either intelligence $(r=.14$, n.s.) or array comparisons $(r=.23$, n.s. $)$.

To address the question of how much variance in the prediction of intelligence is shared between the scope of attention and the control of attention in adults, a regression approach was used. When the attention-benefit ratio and visual array performance scores were used together to predict intelligence, $37 \%$ of the variance in intelligence was accounted for. On that basis, along with regressions in which only one of the predictors was used, one could calculate that $12 \%$ of the variance in intelligence was accounted for by both tasks together, $10 \%$ uniquely by the attention-benefit ratio, and $15 \%$ uniquely by visual array performance. The unique contributions of both variables and their joint contributions all were significant $(p<.01)$. On this basis, one can conclude that the portions of variance in intelligence related to the control of attention and the scope of attention appear to be rather separate mechanisms, at least as measured by these constructs.

Vowel detection did not prove to tap an important source of individual differences related to these other concepts, perhaps because it was so easy for adults (Table 1). Also, as in many other studies with adults, the measures simply involving serial recall of a list (auditory span, visual span, and auditory-only recall) were not good predictors of intelligence (cf. Daneman \& Merikle, 1996).

Children. The pattern of correlations was different for children (Table 2, above the diagonal). The attentionbenefit ratio was not correlated with the other measures, in contrast with the adults. When correlations were examined separately for ignored lists (correlations with IQ composite and array comparison performance) and for attended lists (with the same two variables), none of these correlations was significant $(r=.02, .08, .23$, and .14 , respectively; n.s. in each case). The problem was probably not a lack of reliability for any of the measures; as shown in Table 2, the reliabilities were not very different from those obtained in adults. Inspection of the children's scores showed that several outliers (three with benefit ratios above 1.7 and one with a benefit ratio of below 0.7 ) had midrange IQ composite scores. However, the attention-benefit ratios did fall into a narrower range in children, as noted above ( $S D=$ .29 in children vs. .36 in adults).

In order to understand the meaning of the attentionbenefit ratio, a median split on this variable was carried out separately in the children and the adults, and an ANOVA for attended and ignored lists across all list lengths was examined in each age group. In neither age group was a higher attention-benefit ratio associated with significantly better memory performance overall. In adults, the overall proportion correct with a low ratio was .60; with a high ratio, .63 . In children, the proportion with a low ratio was .59; with a high ratio, .58. In contrast, the IQ composite was significantly lower in participants with a low attention-benefit ratio than with a high ratio (children, -1.52 vs. -1.13 ; adults, 0.98 vs. 1.67 ), though this difference was significant only in adults $(t=3.10)$ and not in children $(t=1.12)$. Therefore, it appears that the attention-benefit ratio reflects the ability or willingness to follow the attention instructions, not the ability to remember items in the lists. One must note that this pattern of results does not imply that young children cannot control attention; indeed, other literature suggests that they can do so to some extent (e.g., Gomes et al., 2000; Lane \& Pearson, 1982). The result suggests only that making use 
of selective attention for mnemonic purposes demanded a level of control that was generally beyond what most of the children - and many of the adults - could manage.

As was the case with the adults, in the children there was a substantial, significant correlation between intelligence and visual array task performance, again confirming the results of Cowan, Elliott, et al. (2005, Experiment 2). The vowel detection task performance was related to visual array performance, but not to intelligence. This common variance might be based on some visual modality-specific perceptual ability that is used to spot colors in arrays and vowels in visually presented sequences.

Cowan, Elliot, et al. (2005) found that contrary to conventional wisdom based on the adult literature, simple auditory span correlated well with intelligence measures in children who were too young to engage in sophisticated rehearsal (see also Hutton \& Towse, 2001). The children in the present paper are at the upper end of this range (see, e.g., Ornstein \& Naus, 1978) and, similar to Cowan, Elliott, et al. (2005), memory for lists in children (visual and auditory spans and performance in the auditory-only condition) were significantly related to intelligence, as shown in Table 2 . These results suggest that when rehearsal is not possible, even simple span tasks may index the scope of attention.

It also is possible for nonattentional, domain-specific components of storage - like the phonological and visuospatial buffers of Baddeley (1986) - to contribute to intelligence measures. To determine how much of the contribution of visual array performance versus span for spoken and printed verbal materials arose from a common pool of variance versus domain-specific skills, a regression on the IQ composite measure was carried out. The regressions indicated that $10 \%$ of the variance in IQ was shared between spans and the visual array task, $11 \%$ was unique to the span tasks, and $9 \%$ was unique to the visual array task. The unique and joint contributions of the span and visual array variables were all significant at $p<.05$ or better. A further breakdown showed that of the $10 \%$ of variance in common with the visual array task, $7 \%$ could be attributed to both the auditory digit and the visual letter span tasks together, and the other 3\% uniquely to the visual letter span task. Similarly, of the $11 \%$ of the variance unique to the span tasks, $6 \%$ could be attributed to both span tasks together, $4 \%$ to the visual letter span task alone, and only $1 \%$ to the spoken digit span task alone. These regression analyses indicate that the amodal, presumably attention-demanding part of memory storage in children exists but is complemented by modality-specific storage.

\section{DISCUSSION}

Many recent studies of working memory have used a procedure in which individuals in the high and low quartiles of working memory span are compared in performance on various tasks (e.g., Bleckley et al., 2003; Conway et al., 2001; Kane et al., 2001; Kane \& Engle, 2003; Unsworth et al., 2004). The present study used a developmental comparison between children and adults as an extreme-group comparison, partly to determine whether analogues to the results that have been observed in past studies of high- and low-span individuals could be obtained. These analogues include better control of attention in high-span individuals (like Kane et al., 2001) and, in these individuals, a greater impact of dividing attention on the recall of incidental materials (like Conway et al., 2001). Indeed, this pattern was obtained in the age group comparison. Important within-group correlations with an intelligence index were also obtained. A summary of results will be followed by a more in-depth discussion of the theoretical implications.

In a task of selective attention in which memory for the attended or ignored modality was tested, there was a pronounced age difference. Although adults performed much better on spoken or printed lists that were fully attended than when attention was split, that was not the case in children. This age difference in the use of attention is clearly evident in both of the slightly different task arrangements used to examine the recall of spoken lists (Figure 2) on one hand and printed lists (Figure 3) on the other. Most strikingly, even when performance on the primary attention task (vowel detection) was matched between age groups, adults were much more able to use full attention for superior encoding and memory, as shown in Figure 4. In children, the differential allocation of attention during encoding in a dual task did not make much difference for memory.

On the basis of these findings, it seems reasonable to conclude that it is the internal control of attention in the service of memory that was poorer in children. Even when they attended to the visual stimuli enough to carry out the primary visual task (vowel detection) as well as adults, this did not leave them able to use this direction of attention for the benefit of memory for the printed letters.

In a visual array comparison task, the capacity estimates were considerably higher in adults than in children and closely replicated the findings of Cowan et al. (2005). There are still some important details to work out in future research, given that Ross-Sheehy, Oakes, and Luck (2003) found higher capacity estimates in infants than we did in children. However, the procedures were very different in these studies. (The changing stimulus was a series of arrays with a change in the color of a different object in each array in the series; therefore, it would be possible to achieve perfect detection even if only a subset of the items were processed.) It is a considerable challenge to find comparable procedures that could allow conclusions about the full life-span development of visual working memory in this sort of task.

Within-age correlations and regressions were quite revealing. Importantly, the present result replicated the finding of Cowan, Elliott, et al. (2005) that performance on the array-comparison task - taken as an indication of the capacity or scope of attention - correlates with intelligence in both adults and children. Also, in the adult group, the amount of benefit from attention to a modality in the list-memory task (in keeping with the instructions) had a high correlation with the intelligence measures. The level of attention demanded by the task may have been too high 
to distinguish among children as clearly; thus, they did not show the effect.

This is one of the first studies in which the correlation that is to be expected (e.g., by Engle et al., 1999) between performance in an attention-allocation task and intelligence measures actually has been directly observed (see also Schweizer \& Moosbrugger, 2004). It is especially important inasmuch as another recent study (Friedman et al., 2006) observed correlations between intelligence and one executive function of working memory (updating), but not between intelligence and two others that also are attention related (shifting and inhibition). The present findings indicate that selective attention to one modality in a bimodal presentation, which is conceptually related to inhibition, can also correlate with intelligence. The explanation for the implied discrepancy with Friedman et al. (2006) must await further research.

We found that adults who recalled more of the to-beignored modality were relatively low in the IQ composite measure (whereas memory for to-be-attended material did not correlate with the IQ measure). This is comparable to the finding of Conway et al. (2001), that individuals who recalled their name in a to-be-ignored auditory channel were relatively low in an operation span measure of working memory. The contribution of the present finding is to establish this point across both modalities and to establish intelligence - and not only working memory — as a distinguishing factor.

The amount of variance in intelligence shared between the attention-control (selective attention) and scope-ofattention (array comparison) tasks in adults was found to be substantial, though less than complete. In particular, $11 \%$ of the variance of the two tasks was shared between them (i.e., the squared correlation), and $12 \%$ of the variance in intelligence was shared with both of these attention-related tasks in common (on the basis of a regression). This was about a third of the $37 \%$ of the variance in intelligence picked up by the two attention-related tasks together, including both joint and unique sources of variance. The use of tasks related to different aspects of attention thus seems quite promising as a way to assist our understanding of intelligence.

In the children, who were young enough so that rehearsal strategies were not fully mature (Bjorklund \& Douglas, 1997; Ornstein \& Naus, 1978), there was a correlation between unimodal list-recall procedures and intelligence, whereas those correlations were not significant in adults. This replicates the pattern observed by Cowan, Elliott, et al. (2005). Simple list recall may partly reflect the scope of attention in children too young to engage in sophisticated rehearsal. Indeed, two of the list-recall measuresvisual span and auditory-only list recall - were significantly related to visual array performance (the primary measure of the scope of attention) in children, but not in adults (see Table 1). A substantial amount (10\%) of the variance in intelligence was accounted for by three simple memory tasks in common (the two span tasks and visual array comparisons). Furthermore, visual and verbal types of memory both made additional, code-specific, unique contributions to the prediction of intelligence of about the same magnitude as their joint contribution.

\section{Theoretical Implications}

The present results have important implications for theories of working memory, attention, intelligence, and their development in childhood. They support current theories that tie working memory to attention and reconcile those that emphasize the control of attention (see, e.g., Engle et al., 1999; Kane et al., 2001) with those that emphasize attention as storage (e.g., Cowan, Elliott, et al., 2005; cf. Anderson, 1983; Just \& Carpenter, 1992; Lovett, Reder, $\&$ Lebière, 1999). In the most frequently cited theory of working memory (Baddeley, 1986; Baddeley \& Logie, 1999), passive storage buffers that hold information automatically and effortlessly are controlled by central executive processes, which consume attention and use it to influence memory encoding and retrieval. In a more recent update of that model (Baddeley, 2000, 2001), there is also storage of more abstract information in a mechanism termed the episodic buffer, the attention requirements of which have not been specified. Thus, the updated model of Baddeley does not necessarily contradict the premise of Cowan $(1988,1995,1999,2001)$ and Cowan, Elliott, et al. (2005), which states that attention can be used not only to control information (as in the present selective attention task), but also to retain information (as in the present visual array comparison task).

Storage of information in the focus of attention presumably supplements storage in the passive buffers of Baddeley (1986) or in the activated portion of long-term memory of Cowan (1988). Storage in the focus of attention presumably makes the information more resistant to interference. For example, Cowan, Johnson, and Saults (2005) carried out a task in which on every trial a probe word was to be judged present or absent from a list that had been presented. Proactive interference from previous lists with semantically similar words occurred for lists that were presumably too long to be held in the focus of attention (those with 6 or 8 words), but not for lists that were presumably short enough to be held in the focus of attention (those with 3 or 4 words). Resistance to interference is important because passive buffers or the activated portion of long-term memory may not have this property. For example, in the array comparison task (Luck \& Vogel, 1997), the second array may overwrite the first before a decision can be made, so retention of an interferenceresistant form of memory is crucial for successful performance of the task.

According to a slightly different view (Oberauer, 2002, 2005), the focus of attention holds only one item and is surrounded by a fringe of up to three or four other items. This view was based on studies in which only a subset of the presented items was eligible for updating and only one of the eligible items was last selected for updating. However, a way to explain such data without postulating multiple discrete levels of attention (the small focus and its larger fringe) is to postulate that the focus of attention is capable of holding three to five independent chunks (Cowan, 
2001), but with an internal prioritization of the items in the focus of attention. Such a prioritization was already required to account for the finding that probed reaction time often differs as a function of serial position in a list, even for lists of one to four items that can be held in the focus of attention (see, e.g., McElree \& Dosher, 1989).

Other theoreticians have attempted to explain individual and developmental differences in working memory and intellectual aptitude. What became the standard view was described for individual differences by Daneman and Carpenter (1980) and for developmental differences by Case et al. (1982). In this view, given that working memory includes both storage and processing components, it is necessary to use working-memory tests that include both storage and processing components. The view was considered successful inasmuch as the correlations between storage-and-processing tests of working memory and tests of intellectual aptitudes were much higher than the correlations between simple storage tests of working memory and these aptitude tests. However, Cowan, Elliott, et al. (2005) showed that comparable high correlations could be obtained with tests that did not include a separate processing component, provided that it was not possible to carry out rehearsal. The presumed reason was that the focus of attention was needed more heavily for storage when rehearsal could not be used, in which case the measure assessed the focus of attention. The present findings reproduce this conclusion by showing once more that high correlations with intelligence were obtained for a storage-only task for which rehearsal is not feasible (visual array comparisons).

In recent years, several theorists have suggested that individual and developmental differences in working memory result from differences in the functions of attention. Engle et al. (1999) and Kane et al. (2001) suggested that what is critical is the ability to control attention. Similarly, others (Gernsbacher, 1993; Hasher, Stoltzfus, Zacks, \& Rypma, 1991; Lustig et al., 1999; May, Hasher, \& Kane, 1999) have suggested that what is critical for working memory is the ability to inhibit irrelevant but often salient information, thereby making the most efficient use of storage. Inhibition can be viewed as an example of the control of attention. Cowan et al. (1995) suggested instead that what is critical is (more generally) the capacity of the focus of attention, which can zoom in to achieve a goal in the presence of interference (e.g., remembering to name the color and not read the word aloud in the task of Stroop, 1935), zoom out to apprehend and concurrently retain as many items as possible (e.g., remembering colored spots in an array in the task of Luck \& Vogel, 1997), or adopt a configuration that is intermediate, attempting to handle both multiple-item retention and interference concurrently (e.g., recalling the part of a list presented in a particular print color if the retrieval cue is presented in a different color; see Bunting \& Cowan, 2005).

However, the present work helps to resolve two important issues that remain open. First, it confirms that the control of attention (Kane et al., 2001) - and not merely attention as it is used for storage (Cowan, Elliott, et al., 2005; Morey \& Cowan, 2004, 2005) or updating (Friedman et al.,
2006) — can be a good predictor of intelligence. Second, it addresses the relation between the control of attention and the use of attention as a storage device. These two concepts, represented by a selective attention task and a visual array comparison task, respectively, were seen to be partly independent and partly overlapping in their relation to each other and to intelligence. This is also a good way to think of these two concepts theoretically. Cowan $(1995,1999)$ argued that the control of attention is represented by a neural system that heavily includes frontal lobe structures, whereas the focus of attention (where the information is held) is represented by a neural system that more heavily includes parietal lobe structures. The argument was based on both differences in the types of impairment that accompany damage to frontal versus parietal areas (Schacter, 1989) and evidence from early neuroimaging studies (Posner \& Petersen, 1990), and it has been further confirmed by more recent research (e.g., Postle et al., 1999). Yet, these two neural systems work together quite closely, and are often referred to in recent literature as a common frontal-parietal system. It therefore makes sense neurally — as well as behaviorally — to think of the control of attention and the focus of attention as mechanisms that are partly overlapping and partly independent from one another.

The present work may also have implications for the measurement and theory of intelligence, as summarized, for example, by Wilhelm and Engle (2005). The traditional approach has been to include in tests of intelligence any subtest that correlates well with success in a criterion measure, such as job or school performance. However, different subtests are likely to emphasize different subsets of skills that may contribute to success (attentional control, memory storage, knowledge, strategic thinking, reasoning, and so on). It would be quite helpful to have tests that are known to indicate particular critical abilities rather than a wide swath of abilities taken together. Given that the combination of attentional control and attentional storage of information appears to correlate well with intelligence measures, it is certainly worth asking in future research how well these aspects of attention and working memory predict success in school or in the workplace.

The present data and other literature lead to expectations that the best predictors of intellectual aptitude will change across childhood. There are at least two bases of expected change. First, as children learn to use verbal rehearsal mechanisms in middle and late childhood, simple measures of memory storage of verbal lists (e.g., digit span) should become poorer predictors of intelligence (cf. Cowan, Elliott, et al., 2005). Second, as frontal lobe areas in the brain mature during childhood and adolescence (see, e.g., Kane \& Engle, 2002; Rabinowicz, 1980; Yakovlev \& Lecours, 1967) and the accompanying improvement in the control of attention takes place (e.g., Guttentag, 1997; Lane \& Pearson, 1982), the variety of attention-control tasks that can be used to predict intelligence should increase. Intertask correlations in the present data set (Table 2) appear to reflect these trends.

In sum, the present study illustrates that the relation between attention and intelligence is real and extends to chil- 
dren as a group who have much lower spans than adults. It should be a priority to carry out further research to investigate different "flavors" of attention task: those that reflect the control of attention and those that reflect its scope, or capacity to apprehend multiple items simultaneously.

\section{REFERENCES}

Anderson, J. R. (1983). The architecture of cognition. Cambridge, MA: Harvard University Press.

Atkinson, R. C., \& Shiffrin, R. M. (1968). Human memory: A proposed system and its control processes. In K. W. Spence \& J. T. Spence (Eds.), The psychology of learning and motivation (Vol. 2, pp. 89195). New York: Academic Press.

BADDELEY, A. [D.] (1986). Working memory. Oxford: Oxford University Press, Clarendon Press.

BAdDELEy, A. [D.] (2000). The episodic buffer: A new component of working memory? Trends in Cognitive Sciences, 4, 417-423.

BADDELEY, A. [D.] (2001). The magic number and the episodic buffer. Behavioral \& Brain Sciences, 24, 117-118.

Baddeley, A. [D.], \& Hitch, G. J. (1974). Working memory. In G. H. Bower (Ed.), The psychology of learning and motivation (Vol. 8, pp. 47-89). New York: Academic Press.

BADDELEY, A. D., \& LogIE, R. H. (1999). Working memory: The multiplecomponent model. In A. Miyake \& P. Shah (Eds.), Models of working memory: Mechanisms of active maintenance and executive control (pp. 28-61). Cambridge: Cambridge University Press.

Bjorklund, D. F., \& Douglas, R. N. (1997). The development of memory strategies. In N. Cowan (Ed.), The development of memory in childhood (pp. 201-246). Hove, U.K.: Psychology Press.

Bleckley, M. K., Durso, F. T., Crutchfield, J. M., Engle, R. W., \& Khanna, M. (2003). Individual differences in working memory capacity predict visual attention allocation. Psychonomic Bulletin \& Review, 10, 884-889.

BunTING, M. F., \& CoWAN, N. (2005). Working memory and flexibility in awareness and attention. Psychological Research, 69, 412-419.

Case, R., Kurland, D. M., \& GoldberG, J. (1982). Operational efficiency and the growth of short-term memory span. Journal of Experimental Child Psychology, 33, 386-404.

CHERRY, E. C. (1953). Some experiments on the recognition of speech, with one and with two ears. Journal of the Acoustical Society of America, 25, 975-979.

Cocchini, G., Logie, R. H., Sala, S. D., MacPherson, S. E., \& BaDDELEY, A. D. (2002). Concurrent performance of two memory tasks: Evidence for domain-specific working memory systems. Memory \& Cognition, 30, 1086-1095.

CoLle, H. A., \& Welsh, A. (1976). Acoustic masking in primary memory. Journal of Verbal Learning \& Verbal Behavior, 15, 17-32.

Conlin, J. A., Gathercole, S. E., \& AdAMS, J. W. (2005). Children's working memory: Investigating performance limitations in complex span tasks. Journal of Experimental Child Psychology, 90, 303-317.

Conway, A. R. A., Cowan, N., \& BunTING, M. F. (2001). The cocktail party phenomenon revisited: The importance of working memory capacity. Psychonomic Bulletin \& Review, 8, 331-335.

Conway, A. R. A., Cowan, N., Bunting, M. F., Therriault, D. J., \& Minkoff, S. R. B. (2002). A latent variable analysis of working memory capacity, short-term memory capacity, processing speed, and general fluid intelligence. Intelligence, 30, 163-183.

CoWAN, N. (1988). Evolving conceptions of memory storage, selective attention, and their mutual constraints within the human informationprocessing system. Psychological Bulletin, 104, 163-191.

Cowan, N. (1995). Attention and memory: An integrated framework. New York: Oxford University Press.

CowAn, N. (1999). An embedded-processes model of working memory. In A. Miyake \& P. Shah (Eds.), Models of working memory: Mechanisms of active maintenance and executive control (pp. 62-101). Cambridge: Cambridge University Press.

Cowan, N. (2001). The magical number 4 in short-term memory: A reconsideration of mental storage capacity. Behavioral \& Brain Sciences, 24, 87-185.

CoWAN, N., \& BARRON, A. (1987). Cross-modal, auditory-visual Stroop interference and possible implications for speech memory. Perception \& Psychophysics, 41, 393-401.

Cowan, N., Elliott, E. M., Saults, J. S., Morey, C. C., Mattox, S., Hismuatullina, A., \& Conway, A. R. A. (2005). On the capacity of attention: Its estimation and its role in working memory and cognitive aptitudes. Cognitive Psychology, 51, 42-100.

Cowan, N., Johnson, T. D., \& SaUlTs, J. S. (2005). Capacity limits in list item recognition: Evidence from proactive interference. Memory, 13, 293-299.

Cowan, N., Nugent, L. D., Elliott, E. M., Ponomarev, I., \& Saults, J. S. (1999). The role of attention in the development of short-term memory: Age differences in the verbal span of apprehension. Child Development, 70, 1082-1097.

DANEMAN, M., \& CARPENTER, P. A. (1980). Individual differences in working memory and reading. Journal of Verbal Learning \& Verbal Behavior, 19, 450-466.

DANEMAN, M., \& MERIKLE, P. M. (1996). Working memory and language comprehension: A meta-analysis. Psychonomic Bulletin \& Review, 3, 422-433.

DOYLE, A. (1973). Listening to distraction: A developmental study of selective attention. Journal of Experimental Child Psychology, 15, 100-115.

DuFf, S. C., \& LogIE, R. H. (2001). Processing and storage in working memory span. Quarterly Journal of Experimental Psychology, 54A, 31-48.

Elliott, E. M., Cowan, N., \& Valle-Inclan, F. (1998). The nature of cross-modal color-word interference effects. Perception \& Psychophysics, 60, 761-767.

Engle, R. W., Tuholski, S. W., Laughlin, J. E., \& Conway, A. R. A. (1999). Working memory, short-term memory, and general fluid intelligence: A latent-variable approach. Journal of Experimental Psychology: General, 128, 309-331.

FrIEDMAN, N. P., \& MiYAKE, A. (2004). The reading span test and its predictive power for reading comprehension ability. Journal of Memory \& Language, 51, 136-158.

Friedman, N. P., Miyake, A., Corley, R. P., Young, S. E., DeFries, J. C., \& HewitT, J. K. (2006). Not all executive functions are related to intelligence. Psychological Science, 17, 172-179.

GATHerCole, S. E., \& BADDELEY, A. D. (1989). Evaluation of the role of phonological STM in the development of vocabulary in children: A longitudinal study. Journal of Memory \& Language, 28, 200-213.

Gernsbacher, M. A. (1993). Less skilled readers have less efficient suppression mechanisms. Psychological Science, 4, 294-298.

Gomes, H., Molholm, S., Christodoulou, C., Ritter, W., \& Cowan, N. (2000). The development of auditory attention in children. Frontiers in Bioscience, 5, D108-D120.

Gray, J. R., Chabris, C. F., \& Braver, T. S. (2003). Neural mechanisms of general fluid intelligence. Nature Neuroscience, 6, 316-322.

Guttentag, R. (1997). Memory development and processing resources. In N. Cowan (Ed.), The development of memory in childhood (pp. 247-274). Hove, U.K.: Psychology Press.

Hasher, L., Stoltzfus, E. R., Zacks, R. T., \& Rypma, B. (1991). Age and inhibition. Journal of Experimental Psychology: Learning, Memory, \& Cognition, 17, 163-169.

HutTon, U. M. Z., \& Towse, J. N. (2001). Short-term memory and working memory as indices of children's cognitive skills. Memory, 9, 383-394.

JoLICEUR, P. (1999). Restricted attentional capacity between sensory modalities. Psychonomic Bulletin \& Review, 6, 87-92.

JonEs, D. (1999). The cognitive psychology of auditory distraction: The 1997 BPS Broadbent Lecture. British Journal of Psychology, 90, 167187.

Just, M., \& CARPEnTER, P. A. (1992). A capacity theory of comprehension: Individual differences in working memory. Psychological Review, 99, 122-149.

Kane, M. J., Bleckley, M. K., Conway, A. R. A., \& Engle, R. W. (2001). A controlled-attention view of working-memory capacity. Journal of Experimental Psychology: General, 130, 169-183.

KANE, M. J., \& ENGLE, R. W. (2000). Working-memory capacity, proactive interference, and divided attention: Limits on long-term memory retrieval. Journal of Experimental Psychology: Learning, Memory, \& Cognition, 26, 336-358. 
Kane, M. J., \& Engle, R. W. (2002). The role of prefrontal cortex in working-memory capacity, executive attention, and general fluid intelligence: An individual-differences perspective. Psychonomic Bulletin \& Review, 9, 637-671.

KANE, M. J., \& ENGLE, R. W. (2003). Working-memory capacity and the control of attention: The contributions of goal neglect, response competition, and task set to Stroop interference. Journal of Experimental Psychology: General, 132, 47-70.

Lane, D. M., \& Pearson, D. A. (1982). The development of selective attention. Merrill-Palmer Quarterly, 28, 317-337.

LÉPINE, R., BARRouillet, P., \& CAMOS, V. (2005). What makes working memory spans so predictive of high-level cognition? Psychonomic Bulletin \& Review, 12, 165-170.

Lovett, M. C., ReDER, L. M., \& Lebière, C. (1999). Modeling working memory in a unified architecture: An ACT-R perspective. In A. Miyake \& P. Shah (Eds.), Models of working memory: Mechanisms of active maintenance and executive control (pp. 135-182). Cambridge: Cambridge University Press.

LuCK, S. J., \& Vogel, E. K. (1997). The capacity of visual working memory for features and conjunctions. Nature, 390, 279-281.

Lustig, C., May, C. P., \& Hasher, L. (2001). Working memory span and the role of proactive interference. Journal of Experimental Psychology: General, 130, 199-207.

MAY, C. P., HASHER, L., \& KANE, M. J. (1999). The role of interference in memory span. Memory \& Cognition, 27, 759-767.

McElree, B., \& Dosher, B. A. (1989). Serial position and set size in short-term memory: The time course of recognition. Journal of Experimental Psychology: General, 118, 346-373.

Míller, G. A. (1956). The magical number seven, plus or minus two: Some limits on our capacity for processing information. Psychological Review, 63, 81-97.

MîAKe, A., \& ShaH, P. (Eds.) (1999). Models of working memory: Mechanisms of active maintenance and executive control. Cambridge: Cambridge University Press.

Moray, N. (1959). Attention in dichotic listening: Affective cues and the influence of instructions. Quarterly Journal of Experimental Psychology, 11, 56-60.

Morey, C. C., \& Cowan, N. (2004). When visual and verbal memories compete: Evidence of cross-domain limits in working memory. Psychonomic Bulletin \& Review, 11, 296-301.

MOREY, C. C., \& COWAN, N. (2005). When do visual and verbal memories conflict? The importance of working-memory load and retrieval. Journal of Experimental Psychology: Learning, Memory, \& Cognition, 31, 703-713.

OBERAUER, K. (2002). Access to information in working memory: Exploring the focus of attention. Journal of Experimental Psychology: Learning, Memory, \& Cognition, 28, 411-421.

OBERAUER, K. (2005). Control of the contents of working memory-A comparison of two paradigms and two age groups. Journal of Experimental Psychology: Learning, Memory, \& Cognition, 31, 714-728.

Oberauer, K., Demmrich, A., Mayr, U., \& KLIegl, R. (2001). Dissociating retention and access in working memory: An age-comparative study of mental arithmetic. Memory \& Cognition, 29, 18-33.

Oberauer, K., Lange, E., \& EngLe, R. W. (2004). Working memory capacity and resistance to interference. Journal of Memory \& Language, 51, 80-96.

ORNSTEIN, P. A., \& NAUs, M. J. (1978). Rehearsal processes in children's memory. In P. A. Ornstein (Ed.), Memory development in children (pp. 69-99). Hillsdale, NJ: Erlbaum.

PASHLER, H. (1988). Familiarity and visual change detection. Perception \& Psychophysics, 44, 369-378.

PENNEY, C. G. (1989). Modality effects and the structure of short-term verbal memory. Memory \& Cognition, 17, 398-422.

Plude, D. J., EnNs, J. T., \& BRODEUR, D. (1994). The development of selective attention: A life-span overview. Acta Psychologica, 86, 227-272.
Posner, M. I., \& Petersen, S. E. (1990). The attention system of the human brain. Annual Review of Neuroscience, 13, 25-42.

Postle, B. R., BERGER, J. S., \& D'Esposito, M. (1999). Functional neuroanatomical double dissociation of mnemonic and executive control processes contributing to working memory performance. Proceedings of the National Academy of Sciences, 96, 12959-12964.

Postle, B. R., DruzGal, T. J., \& D'Esposito, M. (2003). Seeking the neural substrates of visual working memory storage. Cortex, 39, 927-946.

RABINOWICZ, T. (1980). The differentiate maturation of the human cerebral cortex. In F. Falkner \& J. M. Tanner (Eds.), Human growth: Vol. 3. Neurobiology and nutrition (pp. 97-123). New York: Plenum.

Rosen, V. M., \& Engle, R. W. (1997). The role of working memory capacity in retrieval. Journal of Experimental Psychology: General, 126, 211-227.

RosS-SheEhy, S., OAKes, S. M., \& LuCK, S. J. (2003). The development of visual short-term memory capacity in infants. Child Development, 74, 1807-1822.

SALAMÉ, P., \& BADDELEY, A. D. (1982). Disruption of short-term memory by unattended speech: Implications for the structure of working memory. Journal of Verbal Learning \& Verbal Behavior, 21, 150-164.

SCHACTER, D. L. (1989). On the relation between memory and consciousness: Dissociable interactions and conscious experience. In H. L. Roediger III \& F. I. M. Craik (Eds.), Varieties of memory and consciousness: Essays in honour of Endel Tulving (pp. 355-389). Hillsdale, NJ: Erlbaum.

Schweizer, K., \& Moosbrugger, H. (2004). Attention and working memory as predictors of intelligence. Intelligence, 32, 329-347.

Stevanovski, B., \& Jolicceur, P. (2003, November). Attentional limitations in visual short-term memory. Poster presented at the annual meeting of the Psychonomic Society, Vancouver, BC.

Stroop, J. R. (1935). Studies of interference in serial verbal reactions. Journal of Experimental Psychology, 18, 643-662.

THORNDIKe, R. L., HAGEN, E. P., \& SATTLER, J. M. (1986). The StanfordBinet intelligence scale: Fourth edition: Guide for administering and scoring the fourth edition. Chicago: Riverside.

TodD, J. J., \& MaroIs, R. (2004). Capacity limit of visual short-term memory in human posterior parietal cortex. Nature, 428, 751-754.

Tombu, M., \& Jolicceur, P. (2003). A central capacity sharing model of dual-task performance. Journal of Experimental Psychology: Human Perception \& Performance, 29, 3-18.

TuRNER, M. L., \& ENGLE, R. W. (1989). Is working memory capacity task dependent? Journal of Memory \& Language, 28, 127-154.

UnSWORTH, N., ScHROCK, J. C., \& ENGLE, R. W. (2004). Working memory capacity and the antisaccade task: Individual differences in voluntary saccade control. Journal of Experimental Psychology: Learning, Memory, \& Cognition, 30, 1302-1321.

VoGEL, E. K., \& MachIZAWA, M. G. (2004). Neural activity predicts individual differences in visual working memory capacity. Nature, 428, 748-751.

WILHELM, O., \& ENGLE, R. W. (EDS.) (2005). Handbook of understanding and measuring intelligence. London: Sage.

Wood, N., \& Cowan, N. (1995). The cocktail party phenomenon revisited: How frequent are attention shifts to one's name in an irrelevant auditory channel? Journal of Experimental Psychology: Learning, Memory, \& Cognition, 21, 255-260.

Woodman, G. F., Vogel, E. K., \& LucK, S. J. (2001). Attention is not unitary. Behavioral \& Brain Sciences, 24, 153-154.

YaKovlev, P. I., \& LeCours, A. R. (1967). The myelinogenetic cycles of regional maturation of the brain. In A. Minkowski (Ed.), Regional development of the brain in early life (pp. 3-70). Oxford: Blackwell.

(Manuscript received May 29, 2005; revision accepted for publication August 30, 2005.) 